\title{
How safe is the monoplanar access technique for percutaneous nephrolithotomy?
}

\author{
Fatih Oguz $\cdot$ Ramazan Altintas
}

Received: 3 May 2013/Accepted: 16 May 2013/Published online: 28 May 2013

(C) Springer-Verlag Berlin Heidelberg 2013

\section{Dear Sir,}

We read with great interest the recently published article in the esteemed Journal of Urolithiasis, by Hatipoglu et al., entitled "Monoplanar access technique for percutaneous nephrolithotomy." This study is aimed to evaluate the effects of the monoplanar access technique on operative outcomes in percutaneous nephrolithotomy (PNL). The authors suggested that the monoplanar access technique, which is safe to use, decrease puncture time and minimizes direct exposure of the surgeon to radiation, has high success rates [1]. This study is a valuable contribution to the literature which is about the technique of percutaneous renal puncture. But we have some objections to the monoplanar access technique for percutaneous nephrolithotomy the authors have recommended.

Previous studies suggest that renal access, which is one of the most important steps in PNL, has a direct effect on the success rate of the operation [2]. Also ensuring the correct depth of initial percutaneous needle insertion is considered one of the major obstacles in achieving renal access. Biplanar fluoroscopy permits the determination of caliceal orientation and selection of the optimal calix depth for entry [3]. But, with monoplanar access technique, the urologist can see renal caliceal tract as a single vertical plane and cannot see correct renal depth. So monoplanar access technique can be the requirement of multiple punctures, prolonged operative duration and radiological exposure without more experienced urologist. Moreover, success rate of renal access and safe entry can decrease in this technique. Previous studies argue that the biplanar access technique is the safest and successful access technique for percutaneous renal puncture [4]. If there is no biplanar C-arm fluoroscopy, monoplanar access technique can be used with experienced urologists.

Overall, the best access technique for PNL has not been established yet. We do imply that trials to compare two different techniques are obviously awaited for rendering its success in the PNL.

Conflict of interest None.

\section{References}

1. Hatipoglu NK, Bodakci MN, Penbegül N, Bozkurt Y, Sancaktutar AA, Atar M, Söylemez H (2013) Monoplanar access technique for percutaneous nephrolithotomy. Urolithiasis. doi:10.1007/s00240013-0557-8

2. Marcovich R, Smith AD (2005) Percutaneous renal access: tips and tricks. BJU Int 95(Suppl 2):78-84

3. Miller NL, Matlaga BR, Lingeman JE (2007) Techniques for fluoroscopic percutaneous renal access. J Urol 178(1):15-23

4. Shergill IS, Abdulmajed MI, Moussa SA, Rix GH (2012) The 3-finger technique in establishing percutaneous renal access: a new and simple method for junior trainees. J Surg Educ 69(4):550-553. doi:10.1016/j.jsurg.2012.03.004
F. Oguz $(\bowtie) \cdot$ R. Altintas

Department of Urology, Faculty of Medicine,

Inonu University, 44280 Malatya, Turkey

e-mail: drfoguz@gmail.com

R. Altintas

e-mail: ramazan449@yahoo.com 